\title{
A State-Level Analysis of the Great Moderation*
}

\author{
Michael T. Owyang, Jeremy Piger, and Howard J. Wall ${ }^{\dagger}$ \\ Research Department \\ Federal Reserve Bank of St. Louis \\ P.O. Box 442 \\ St. Louis, MO \\ 63166
}

\section{Preliminary Draft}

Keywords: disaggregation, volatility reduction, Markov-switching

January 5, 2006

\begin{abstract}
A number of studies have documented a reduction in aggregate macroeconomic volatility beginning in the early 1980s. Using an empirical model of business cycles, we extend this line of research to state-level employment data, find significant heterogeneity in the timing and magnitude of the state-level volatility reductions. In fact, some states experience no statistically-significant reduction in volatility. We then exploit this cross-sectional heterogeneity to evaluate three hypotheses about the origin of the aggregate volatility reduction. We show that states with relatively higher manufacturing concentration experience later breaks, a result that tends to contradict improved inventory management and a decline in the volatility of productivity shocks as possible explanations. Our results, then, are more consistent with monetary policy as the origin of the aggregate volatility reduction.
\end{abstract}

[JEL: C22, E24, E32]

${ }^{*}$ The authors thank Michelle T. Armesto and Kristie M. Engemann for research assistance. This paper benefited from conversations with Jim Hamilton and Valerie Ramey. Views expressed here are the authors' alone and do not reflect the opinions of the Federal Reserve Bank of St. Louis or the Federal Reserve System. The usual disclaimers apply.

${ }^{\dagger}$ Corresponding author: wall@stls.frb.org 


\section{Introduction}

The U.S. economy has experienced a number of dramatic changes during the post-War period. One of these changes - a decline in the volatility of a broad range of macroeconomic variables - occurred in the early 1980s. Researchers have documented the presence of structural breaks in the volatility of a number of time series, including GDP [Kim and Nelson 1999a; McConnell and Perez-Quiros 2000], consumption [Chauvet and Potter 2001], and prices [Stock and Watson 2002]. So pervasive is the evidence for an aggregate volatility reduction that, in a speech on February 20, 2004 at the Eastern Economic Association Meetings, then-Federal Reserve Governor Ben Bernanke described the phenomenon as "The Great Moderation."

While evidence relating to the existence of the volatility reduction abounds, explanatory unanimity has proved more elusive. Three theories have been suggested. First, innovations to inventory management such as just-in-time production may have significantly smoothed output [Kahn, McConnell, and Perez-Quiros 2000]. If true, the inventory story manifests itself in a decline in the inventory-to-sales ratio, especially for durable goods. ${ }^{1}$ Second, changes in monetary policy brought about by the Volcker-Greenspan era might have dampened the effect of economic fluctuations [Boivin and Giannoni 2003]. Here, a reduction in the Federal Reserve's reaction to output fluctuations relative to inflation might have led to more-stable monetary policy and more-stable output growth. Finally, the nature of the innovations themselves might have changed, becoming smaller and, in some cases such as oil shocks, less frequent [Ahmed, Levin, and Wilson 2004]. This explanation - call it good luck - hinges on a reduction in volatility across the entire spectrum of shocks, especially high-frequency innovations.

\footnotetext{
${ }^{1}$ For alternative perspectives on the role of inventory management, see Herrera and Pesavento (forthcoming) and Ramey and Vine (2004).
} 
Among the numerous subsequent studies that have sought to determine the causality behind the decline in macroeconomic volatility, several papers have investigated the extent to which the phenomenon has pervaded disaggregated data. In particular, the reduction in volatility is exhibited in both the disaggregated components of output and in industry classifications such as manufacturing [Kim, Nelson, and Piger 2004; Stock and Watson 2002]. One area left unexplored is geographical disaggregation. In a recent paper, Owyang, Piger, and Wall (2005) used an empirical model based on the Markov-switching model of Hamilton (1989) to examine cross-sectional variation in the timing and magnitude of state-level business cycles. Using state-level coincident indices based on employment measures [see Crone and Clayton-Matthews 2005], they found that state business cycles, though similar to the national cycle, exhibited idiosyncratic characteristics that depended on demographics and industrial composition. An advantage of this vein of study is that business cycles are explicitly modeled, which allows separate treatment of changes in business cycle characteristics and higher-frequency innovations. ${ }^{2}$ Moreover, geographical disaggregation damps out industry-level idiosyncratic shocks that tend to completely disassociate industry cycles from the national business cycle.

In this paper, we reexamine the Great Moderation using state-level empirical business cycle models. Estimation of the state-level models affords us a panel of pre- and post-break business cycle characteristics for each state. Similarly, because we allow for idiosyncratic variation in the timing of each state's volatility reduction, we obtain a cross section that can be used to evaluate the three explanations for the volatility reduction - inventories, monetary policy, and good luck.

The remainder of the paper is as follows: Section 2 examines the evidence for a reduc-

\footnotetext{
${ }^{2}$ Anderson and Vahid (2003) and Carlino, DeFina, and Sill (2004) have also considered geographicallydisaggregated empirical models of the volatility reduction. These models, however, do not explicitly model business cycles or compute the state-level contribution to the aggregate volatility reduction.
} 
tion in the volatility of aggregate employment. Section 3 performs a similar exercise but at the state-level. Section 4 decomposes the aggregate volatility reduction into contributions from each state's business cycle and conditional variance. Section 5 considers the three hypotheses for explaining the volatility reduction in the context of the state-level evidence. In particular, we consider elements such as differential timing and magnitude to determine if the state-level cross-section can exclude any of the aforementioned explanations. Section 6 concludes.

\section{The Volatility Reduction in Aggregate Employment}

Many recent papers have discussed the nature of the volatility reduction in aggregate GDP and other variables. Our focus on employment is motivated by a lack of a suitable alternative GDP series at the state level. For this and subsequent sections, the data we use are seasonally adjusted, monthly payroll employment from the Bureau of Labor Statistics. Each of the models is estimated in annualized growth rates. To ease comparison between the national and state-level models, the aggregate model is estimated using the growth rate constructed from the sum of the levels of the 48 contiguous states and the District of Columbia. All series extend from 1956:02 through 2004:12.

\subsection{Model}

Our model is a straightforward extension of the Markov-switching model of Hamilton (1989) in which we suppress the autoregressive dynamics for simplicity. A benefit of the Markovswitching model is its explicit representation of business cycle phases. ${ }^{3}$ In addition, we allow for the possibility of a structural break in the regime-dependent steady-state growth

\footnotetext{
${ }^{3}$ An alternate approach to our strategy is employed by Ahmed, Levin, and Wilson (2004), who perform a spectral decomposition of some aggregate macroeconomic series.
} 
rates of employment as well as the conditional variance of employment. Let $Y_{t}$ reflect the growth rate of aggregate employment; then,

$$
Y_{t}=\left(\mu_{0, A}+\mu_{1, A} S_{t}\right)\left(1-D_{t}\right)+\left(\mu_{0, B}+\mu_{1, B} S_{t}\right) D_{t}+\eta_{t}
$$

where $\lambda=\left[\mu_{0, A}, \mu_{1, A}, \mu_{0, B}, \mu_{1, B}\right]^{\prime}$ is a vector of parameters determining the regime-dependent steady-state growth rates, $\eta_{t} \backsim N\left(0, \sigma_{A}^{2}(1-D t)+\sigma_{B}^{2} D_{t}\right), \sigma_{A}^{2}$ and $\sigma_{B}^{2}$ are regime-dependent conditional variances, and $D_{t}$ is a dummy variable that indicates the timing of the structural break $\tau$ such that

$$
D_{t}=\left\{\begin{array}{c}
0, t<\tau \\
1, t \geq \tau
\end{array} .\right.
$$

In addition to the structural break, the economy experiences business cycles governed by a first-order hidden Markov variable $S_{t}$, which has transition probabilities

$$
\begin{aligned}
& P\left[S_{t}=0 \mid S_{t-1}=0\right]=q_{A}\left(1-D_{t}\right)+q_{B} D_{t}, \\
& P\left[S_{t}=1 \mid S_{t-1}=1\right]=p_{A}\left(1-D_{t}\right)+p_{B} D_{t},
\end{aligned}
$$

which also are subject to the structural break.

\subsection{Estimation}

The model in the preceding subsection is estimated with the Gibbs sampler [Gelfand and Smith 1990]. ${ }^{4}$ Use of the Gibbs sampler requires prior distributions chosen by the econome-

\footnotetext{
${ }^{4}$ The Gibbs sampler is a Markov-chain Monte Carlo procedure in which the joint distribution for all parameters is obtained via sampling from the conditional distributions of each parameter. Repeated iterations of draws from the individual conditional densities produces a collection of draws that form the ergodic distribution for the full set of parameters, including the break date $\tau$.
} 
trician. In this case, we assume that (i) the parameter vector $\lambda$ has a multivariate normal prior distribution, (ii) each conditional variance has an inverse gamma prior distribution, and (iii) each transition probability has a beta prior distribution. ${ }^{5}$ Each distribution is parameterized to yield a proper, yet diffuse prior. To capture the volatility reduction, we assume the break parameter $\tau$ has a discrete uniform prior distribution over all possible break dates. Given these prior distributions, estimation using the Gibbs sampler is straightforward. The hidden Markov variable is drawn from the procedure discussed in Kim and Nelson (1999b). Conditional on the draws for the parameter vectors, the break date can be drawn from the following distribution [Carlin, Gelfand, and Smith 1992]:

$$
\tau \backsim p\left(\tau \mid Y, \lambda, \sigma_{A}^{2}, \sigma_{B}^{2}, \pi\right)=\frac{L\left(Y ; \tau, \lambda, \sigma_{A}^{2}, \sigma_{B}^{2}, \pi\right)}{\sum L\left(Y ; \tau, \lambda, \sigma_{A}^{2}, \sigma_{B}^{2}, \pi\right)},
$$

where $\pi=\left[q_{A}, q_{B}, p_{A}, p_{B}\right]$ and

$$
L\left(Y ; \tau, \lambda, \sigma_{A}^{2}, \sigma_{B}^{2}, \pi\right)=\frac{\exp \left[-\sum_{i} \frac{1}{2 \sigma_{i}^{2}} \varepsilon_{i}^{(\tau) \prime} \varepsilon_{i}^{(\tau)}\right]}{\sigma_{A}^{\tau} \sigma_{B}^{T-\tau}} .
$$

In the expression above, $\boldsymbol{\varepsilon}_{A}^{(\tau)}$ is the $\tau \times 1$ vector of pre-break errors conditional on $\tau, \boldsymbol{\varepsilon}_{B}^{(\tau)}$ is its $(T-\tau) \times 1$ post-break counterpart.

To evaluate the evidence in favor of the model with a structural break, we estimate the model above without the structural break, denoted $M_{0}$, and with the structural break, denoted $M_{1}$, and compute the marginal data density for each model $p\left(Y \mid M_{j}\right), j=0,1$. The evidence is favor of $M_{1}$ is then summarized by the Bayes Factor:

$$
B_{10}=\frac{p\left(Y \mid M_{1}\right)}{p\left(Y \mid M_{0}\right)}
$$

\footnotetext{
${ }^{5}$ At each iteration $n$, any parameter $x$ is drawn conditional on the draws for all other parameters, the data, and that iteration's break date draw, $\tau^{[n]}$.
} 
Jeffreys (1961) provides a log scale for the interpretation of $B_{10}$ given as follows:

\begin{tabular}{|c|c|}
\hline$B_{10}<0$ & $M_{0}$ preferred \\
\hline $0<\ln \left(B_{10}\right)<1.2$ & Very slight evidence in favor of $M_{1}$ \\
\hline $1.2<\ln \left(B_{10}\right)<2.3$ & Slight evidence in favor of $M_{1}$ \\
\hline $2.3<\ln \left(B_{10}\right)<4.6$ & Strong evidence in favor of $M_{1}$ \\
\hline $\ln \left(B_{10}\right)>4.6$ & Decisive evidence in favor of $M_{1}$ \\
\hline
\end{tabular}

Intuition for the Jeffreys scale can be obtained by noting that with equal prior probability given to $M_{0}$ and $M_{1}$, so that $p\left(M_{0}\right)=p\left(M_{1}\right)$, the Bayes Factor is equivalent to the posterior odds in favor of $M_{1}$ :

$$
B_{10}=\frac{p\left(M_{1} \mid Y\right)}{p\left(M_{0} \mid Y\right)}
$$

Thus, "strong" evidence on the Jeffreys scale indicates that model $M_{1}$ is deemed to be $e^{2.3}=10$ times (or greater) more likely than $M_{0}$.

\section{$2.3 \quad$ Results}

Estimation of the model in the previous section yields a number of results that confirm the presence of a volatility reduction in aggregate employment. The log Bayes factor in favor of the model with a break versus the model with no break is 20.9, providing definitive evidence of a structural break using Jeffreys scale. The posterior median of the break date is September 1984, and the 5th and 95th percentiles of the break date are March 1984 and May 1985. ${ }^{6}$ Moreover, the break affects multiple aspects of the aggregate

\footnotetext{
${ }^{6}$ McConnell and Perez-Quiros (2000) document the structural break in volatility of GDP in the first quarter of 1984. Not surprisingly, the median volatility reduction in aggregate employment occurs slightly later. All break dates cited in the literature, however, lie within $5^{\text {th }}$ and $95^{\text {th }}$ percentiles of the posterior distribution for our aggregate employment break.
} 
employment process, corresponding to a reduction in $\sigma^{2}$ (reduction in residual variance), a decline in the absolute value of both $\mu_{0}$ and $\mu_{1}$ (recessions are less severe; expansions are less robust), and an increase in both $p$ and $q$ (business cycle phases last longer). The ratio of the unconditional standard deviation of $Y_{t}$ after the break to the unconditional standard deviation of $Y_{t}$ before the break has a posterior median of 0.573 , with $5^{\text {th }}$ and $95^{\text {th }}$ posterior percentiles of $0.572,0.582$. Thus, the structural break corresponds to a roughly 60 percent reduction in the volatility of $Y_{t}$. With these results in mind, we now decompose the aggregate volatility reduction into its state-level elements.

\section{State-Level Volatility Reduction}

In our previous paper, we considered the notion that each state-level business cycle might be unique yet related to the more frequently studied national cycle. In this section, we extend this notion to determine the extent of each state's volatility reduction using a model of state-level business cycles.

\subsection{Model}

The model for an individual state $i$ 's employment growth rate is analogous to the model for aggregate employment growth:

$$
y_{i t}=\left(\mu_{i 0, A}+\mu_{i 1, A} S_{i t}\right)\left(1-D_{i t}\right)+\left(\mu_{i 0, B}+\mu_{i 1, B} S_{i t}\right) D_{i t}+\eta_{i t}
$$

where $\eta_{i t} \backsim N\left(0, \sigma_{i, A}^{2}(1-D i t)+\sigma_{i, B}^{2} D_{i t}\right)$. The state-level transition probabilities are 


$$
\begin{aligned}
& P\left[S_{i t}=0 \mid S_{i t-1}=0\right]=q_{i, A}\left(1-D_{i t}\right)+q_{i, B} D_{i t}, \\
& P\left[S_{i t}=1 \mid S_{i t-1}=1\right]=p_{i, A}\left(1-D_{i t}\right)+p_{i, B} D_{i t},
\end{aligned}
$$

and

$$
D_{i t}=\left\{\begin{array}{c}
0, t<\tau_{i} \\
1, t \geq \tau_{i}
\end{array}\right.
$$

Here, we have assumed that each state has an idiosyncratic business cycle governed by its own hidden Markov variable $S_{i t}$. Further, each state is allowed to experience a volatility reduction with idiosyncratic timing $\tau_{i}$. To focus on the breaks associated with the volatility reduction, $\tau_{i}$ is restricted to be within ten years on either side of the posterior median of the aggregate break date, i.e., between October 1974 and August 1994. Estimation for each state is as described in the previous section. As above, we estimate the model with and without a break for each state to determine the likelihood of a break in all parameters.

\subsection{Results}

Figure 1 about here.

Figure 1 summarizes the state-level evidence for the model with a break, as summarized by the log Bayes factors. The model with a break is preferred for all but six states - the District of Columbia, Georgia, Maine, Maryland, New York, South Carolina, and West Virginia - all states located near or on the Atlantic coast. For 38 states, the log Bayes Factor is greater than 2.3, meaning there is strong evidence for a structural break using the Jeffreys scale. The additional exceptions to the states listed above are Massachusetts, 
Nebraska, Tennessee, and Vermont.

Some of the states for which there is strong evidence of a break experience their volatility reduction outside three years of the estimated aggregate break date. Figure 1 also separates from the rest those states which exhibit strong evidence of a break within three years of the median date for the aggregate - just over half (27) of the states. ${ }^{7}$ These states appear to be the primary influence on the timing of the aggregate break. ${ }^{8}$

Figure 2 about here.

Figure 2 gives the posterior median of each state's break date, with lighter colors indicating an earlier break. These results highlight the substantial heterogeneity in the timing of each state's volatility reduction, which appears to be influenced by geographic contiguity. Specifically, the figure suggests some geographical clustering of the break dates, with states in the Far West experiencing the volatility reduction first followed by the Midwest and Great Lakes. Moreover, some states do not experience a decline in volatility, with these states mostly located in New England and the Mideast.

Figure 3 about here.

Figure 3 illustrates the posterior median of the ratio of the unconditional standard deviation of $y_{i t}$ in the pre- and post-break periods. ${ }^{9,10}$ Darker-colored states have a lower volatility ratio, indicating a higher reduction in variance. Only the District of Columbia

\footnotetext{
${ }^{7}$ The $90 \%$ posterior error bands include the aggregate posterior median break date for less than half (23) of the states. Results for the posterior $5^{t h}$ and $95^{t h}$ percentiles for the break date are available on request.

${ }^{8}$ A state's influence on the aggregate break date is a function of the size of its labor force, the magnitude of the break, and, perhaps, its initial volatility. We further investigate each state's influence on the aggregate volatility reduction below.

${ }^{9}$ Figure 3 illustrates the ratio of volatilities regardless of whether or not the break is preferred.

${ }^{10} \mathrm{In}$ addition, we note that many state-level business cycles became more persistent, i.e., both transition probabilities $p$ and $q$ rose after the break.
} 
has a ratio greater than one, meaning that volatility actually increased after the break. Recall, however, that D.C. is one case for which the model with no structural break was the preferred model. For the other states, the largest volatility reduction occurred in Arkansas, for which the volatility ratio is 0.47 , while the smallest occurred in South Carolina, for which the ratio is 0.87. Again, South Carolina is a state for which the model with no structural break is preferred. For 29 of the states, the volatility ratio is greater (meaning the volatility reduction is smaller) than for the aggregate data.

Figure 4 about here.

Figure 4 illustrates the portion of the total reduction in state-level volatility attributable to the decline in business cycle variation. In other words, Figure 4 measures the fraction of the decline in state-level variance $\Delta V\left(y_{i t}\right)$ attributable to reductions in $\mu_{1}$ and the Markov

process governing $S_{t}$. Comparison of Figures 3 and 4 shows that many of the states for which the volatility reduction was large and heavily driven by declining business cycle variation are collected in the Great Lakes region. Moreover, for many Rocky Mountain and Plains states, the decline in business cycle volatility accounts for only a small fraction of the total reduction in state variance. One possible explanation for this result is that these states experienced greater business cycle fluctuations than other states caused by the geographically-isolated downturn that occured during the mid-1980s [Owyang, Piger, and Wall 2005].

\section{Decomposition of the Volatility Reduction}

In addition to providing a cross-section with which we can analyze the Great Moderation, the disaggregated model can determine the contribution of each state to the aggregate 
volatility reduction. Further, we can determine whether the aggregate volatility reduction is a result of a reduction in the conditional volatility of individual states, a reduction in the magnitudes of state-level business cycle fluctuations, or both. ${ }^{11}$

\subsection{Weights Counterfactuals}

The aggregate growth rate can be rewritten as a weighted sum of the state-level growth rates:

$$
Y_{t}=\sum_{i} w_{i t} y_{i t}
$$

where $w_{i t}$ are time-location-specific weights for which $\sum_{i} w_{i t}=1$. Fluctuations in the weights complicate matters as they prevent straightforward analytical solutions for the decomposition. Thus, we first determine the effect on aggregate volatility reduction of fluctuations in the weights over time. We accomplish this by executing the following counterfactual experiment. ${ }^{12}$

First, we obtain a draw from the posterior distributions of $\lambda_{i}, \tilde{S}_{i, A}=\left(S_{i 1}, S_{i 2}, \ldots ., S_{i \tau_{i}-1}\right)^{\prime}$ and $\tilde{S}_{i, B}=\left(S_{i \tau_{i}}, S_{i \tau_{i}+1}, \ldots ., S_{i T}\right)^{\prime}$, where $\tau_{i}$ is not estimated, but is instead set equal to the median of the posterior distribution of the aggregate break date, September 1984, for all $i$. Second, we use these draws to construct model residual vectors,

$$
\tilde{\eta}_{i, A}=\widetilde{y}_{i, A}-\mu_{i 0, A}-\mu_{i 1, A} \tilde{S}_{i, A} \text { and } \tilde{\eta}_{i, B}=\widetilde{y}_{i, B}-\mu_{i 0, B}-\mu_{i 1, B} \tilde{S}_{i, B}
$$

where $\widetilde{y}_{i, A}=\left(y_{i 1}, y_{i 2}, \ldots ., y_{i \tau_{i}-1}\right)^{\prime}$ and $\widetilde{y}_{i, B}=\left(y_{i \tau_{i}}, y_{i \tau_{i}+1}, \ldots ., y_{i T}\right)^{\prime}$. Third, define

\footnotetext{
${ }^{11}$ In this section, we assume the median estimated aggregate break date for all states for tractability.

${ }^{12}$ For the counterfactual experiments performed in this section it will be useful to have the same amount of data on either side of the aggregate break date, which again is September 1984. Thus, we shorten the sample to run from May 1964 - December 2004. The size of the volatility reduction in the aggregate over these two sub-samples is similar to that in the longer sample discussed in Section 2.
} 


$$
\tilde{w}_{i, A}=\left(w_{i 0}, w_{i 1}, \ldots . ., w_{i \tau_{i}-2}\right)^{\prime} \text { and } \tilde{w}_{i, B}=\left(w_{i \tau_{i}-1}, w_{i \tau_{i}}, \ldots . ., w_{i T-1}\right)^{\prime}
$$

Finally, we can use these draws to construct a counterfactual aggregate growth rate series

$$
\widetilde{Y}=\sum_{i}\left(\mu_{i 0, A}+\mu_{i 1, A} \tilde{S}_{i, A}+\tilde{\eta}_{i, A}\right) \bullet \tilde{w}_{i, B}
$$

where $\bullet$ represents element-by-element multiplication. In (4), the weights are set to the post-break values, while all other variables are set at the pre-break values. We then compute the standard deviation of the counterfactual aggregate growth rate series to see how much of the observed volatility reduction can be explained by weights. ${ }^{13}$ We find that changes in the weights have played a relatively small role in the aggregate volatility reduction and that changes in the weights alone cannot generate any volatility reduction. ${ }^{14,15}$

\subsection{Analytical decomposition based on fixed weights}

Under the assumption that the weights are constant, we return to (3) to compute the marginal effects of changes in each state's business cycle and conditional variance on the aggregate reduction in volatility. Rewrite (3) by substitution

$$
Y_{t}=\sum_{i} w_{i t} y_{i t}=\sum_{i} w_{i t}\left[\left(\mu_{i 0}+\mu_{i 1} S_{i t}\right)+\eta_{i t}\right]
$$

Then, the unconditional variance of aggregate employment is

\footnotetext{
${ }^{13}$ These steps are repeated for each of $J$ draws from the posterior distribution. The discussion that follows is based on the posterior median from these $J$ draws.

${ }^{14}$ This is consistent with the findings of Anderson and Vahid (2003).

${ }^{15}$ We conducted a similar counterfactual experiment to investigate the role of changes in the persistence of the hidden Markov variable $S_{i t}$. We found that changes in $S_{i t}$ play a relativelt small role in the aggregate volatility reduction.
} 


$$
\begin{aligned}
V\left(Y_{t}\right) & =\sum_{i} w_{i t}^{2} V\left(y_{i t}\right)+\sum_{i} \sum_{j \neq i} w_{i t} w_{j t} C\left(y_{i t}, y_{j t}\right) \\
& =\sum_{i} w_{i t}^{2}\left[\mu_{i 1}^{2} V\left(S_{i t}\right)+\sigma_{i}^{2}\right]+\sum_{i} \sum_{j \neq i} w_{i t} w_{j t} \mu_{i 1} \mu_{j 1} C\left(S_{i t}, S_{j t}\right)+\sum_{i} \sum_{j \neq i} w_{i t} w_{j t} \sigma_{i} \sigma_{j} \rho_{i j},
\end{aligned}
$$

where $V(\cdot)$ indicates a variance, $C(\cdot, \cdot)$ indicates a covariance. ${ }^{16}$ The variance of the hidden Markov variable depends on the transition probabilities through

$$
V\left(S_{i t}\right)=\frac{\left(1-q_{i}\right)\left(2-p_{i}-q_{i}\right)-\left(1-q_{i}\right)^{2}}{\left(2-p_{i}-q_{i}\right)^{2}} .
$$

Thus, the marginal contributions from changes in each state's business cycle magnitude $\left(\mu_{1 i}\right)$ and each state's unconditional variance $\left(\sigma_{i}^{2}\right)$ can be approximated from the following:

$$
\begin{gathered}
\delta_{\sigma_{i}^{2}}=\frac{\partial V\left(Y_{t}\right)}{\partial \sigma_{i}^{2}} \Delta \sigma_{i}^{2}=\left[w_{i}^{2}+\frac{1}{2} \sum_{j \neq i} w_{i} w_{j} \frac{\sigma_{j}}{\sigma_{i}} \rho_{i j}\right] \Delta \sigma_{i}^{2}, \\
\delta_{\mu_{i 1}}=\Delta \mu_{i 1}\left[2 w_{i}^{2} \mu_{i 1}\left(1-q_{i}\right) \frac{\left(2-p_{i}-q_{i}\right)-\left(1-q_{i}\right)}{\left(2-p_{i}-q_{i}\right)^{2}}+2 w_{i} w_{j} \mu_{j} \widehat{\rho}_{S_{i} S_{j}}\right]
\end{gathered}
$$

and

$$
\delta_{\rho, w}=\Delta \widehat{V}\left(Y_{t}\right)-\delta_{\mu_{i 1}}-\delta_{\sigma_{i}^{2}}
$$

In $(9), \Delta \widehat{V}\left(Y_{t}\right)$ is the sample change in aggregate volatility and $\delta_{k}$ indicates the contribution to the aggregate volatility reduction from variable $k$. In (6), we replace the cross-state business cycle correlation $\rho_{S_{i} S_{j}}$ with the sample correlation, $\widehat{\rho}_{S_{i} S_{j}}$ at each iteration of the

\footnotetext{
${ }^{16}$ In deriving this relationship, we assume that the hidden Markov variable and the innovation term are uncorrelated within and between states. The former is an explicit assumption of the filter used in the estimation. The latter does not seem to be an unreasonable approximation and lends tractability.
} 
Gibbs sampler. The residual $\delta_{\rho, w}$ defined in (7) yields the contribution of changes in crossstate business cycle correlation and encompasses any error that occurs from averaging the weights.

\subsection{Results}

Conditional on the average weights for the pre-break period, we find that 32 percent of the aggregate volatility reduction can be attributed to reductions in state idiosyncratic residual variances, $\sigma_{i}^{2}$. An additional 40 percent of the aggregate reduction was accounted for by a decline in the magnitude of state-level business cycles, $\mu_{1 i}$. Individual results for each state's contribution to the aggregate volatility reduction are provided in Table 1.

Table 1 about here

From Table 1, it can be seen that the majority of the aggregate volatility reduction can be attributed to a small group of states. Since the weight in equations (5) through (7) play an important role, the states with the largest population have the most significant impact on the aggregate volatility reduction. Perhaps not surprisingly, California, Illinois, Indiana, Michigan, Ohio, Pennsylvania, and Texas are the only states that each account for more than 1 percent of the aggregate reduction for both $\sigma_{i}^{2}$ and $\mu_{1 i}$. These seven states alone account for 41.7 percent of the decline in aggregate volatility. ${ }^{17}$ Interestingly, more than half of the states (31) contribute no more than 1 percent each to the aggregate volatility reduction through both their business cycle and idiosyncratic components.

While the results from this analysis indicate that population plays an important role

\footnotetext{
${ }^{17}$ These states' reduction in idiosyncratic variance and business cycle volatility account for 16.6 and 25.1 percent of the aggregate reduction, respectively. In addition to these eight states, three others - Florida, Minnesota, and Wisconsin - have business cycle volatility reductions that exceed 1 percent of the aggregate. Missouri, New Jersey, New York are the only other states that contribute at least 1 percent of the aggregate volatility reduction through a decline in idiosyncratic variance.
} 
in the composition of the Great Moderation, Table 1 also highlights that the phenomenon is geographically-oriented toward the industrial states surrounding the Great Lakes. A disproportionate amount of the aggregate volatility reduction results from these states in which manufacturing plays an important role. While these results are suggestive, we cannot yet exclude any of the prevailing theories on the origin of the aggregate volatility reduction. We address this issue in the next section.

\section{Testing Hypotheses for the Great Moderation}

In prior sections, we have documented the state-level heterogeneity in the timing, magnitude, and composition of the volatility reduction in total payroll employment. Here, we attempt to reconcile these results with the three proposed hypotheses for the origins of the aggregate volatility reduction associated with the Great Moderation. To this end, we exploit the cross-sectional variability in state-level breaks to uncover possible statistical relationships between the characteristics of these breaks and other, pre-break state characteristics.

Specifically, we perform OLS estimation using the volatility ratio (Figure 3) and the break dates (Figure 2) as our dependent variables. To test for the influence of the various hypotheses, our independent variables are the nondurable and durable employment shares, the extractive-industries employment share, average firm size, and the deposit share at the three largest banks. ${ }^{18}$ In addition, to control for changes in the composition of the labor force that might account for some of the change in employment volatility, we also include the population share aged 18-44 and the percentage of those aged 25 and older who have

\footnotetext{
${ }^{18}$ The nonduranble-goods, duranble-goods, and extractive industries employment shares are averaged over 1969-83 and are from the BLS ; average firm size is for 1988 and is from the Census Bureau's Statistics of U.S. Business; the deposit share of the three largest banks is for 1983 and is from the State and Metro Area Data Book, 1986. For the last two variables, we used the first year for which data are available, assuming that they are useful proxies for the state-level variations for the pre-break period.
} 
at least four years of high school. ${ }^{19}$

According to the inventory hypothesis, innovations in inventory management in the durable-goods sectors have led to reductions in the volatility of output. If this hypothesis holds, we should see a negative relationship been the volatility ratio and the durable-goods share, but not the nondurable-goods share, thereby indicating that states that produce relatively more durable goods tended to see the largest reductions in volatility. In addition, states that produced relatively more durable goods should tend to have experienced their breaks earlier than average, so we would expect that there would be a negative relationship between the break date and the durable-goods employment share.

According to the good-luck hypothesis, the reduction in output volatility was associated with reductions in the volatility of various (and often unspecified) innovations and shocks. These shocks and innovations can come from a myriad of sources, two of which we control for in our regressions: energy shocks and productivity shocks. If reductions in the volatility of energy prices have led to reductions in output volatility, we should find that the volatility ratio is negatively related to the extractive-industries employment share. Similarly, if reductions in the volatility of productivity shocks have led to reductions in output volatility, we should find that the volatility ratio is negatively related to the shares of employment in nondurable-goods and durable-goods production. If reductions in the volatility of either of these shocks have been causal in driving the volatility reduction in output, then a state with relatively high extractive-industries share, nondurable-goods share, or durable-goods share should have seen an earlier-than-average break.

According to the view that it was reductions in the volatility of monetary policy that led to reductions in output volatility, the Fed has changed the way in which it reacts to inflation and output tradeoffs, meaning that it has become less willing to try to fine tune

\footnotetext{
${ }^{19}$ Both of these variables are averaged over 1970 and 1980 and are from the decennial census.
} 
the output side of the economy by adjusting monetary policy, thereby reducing output volatility. If the monetary hypothesis is correct, we should see statistical relationships between the sizes and timing of volatility reductions and measures of the three channels of monetary policy: the money channel, the broad credit channel, and the narrow credit channel. ${ }^{20}$

Through the money channel, because durable-goods industries are relatively interestrate sensitive, the largest volatility reductions should be in states with large durable-goods sectors, i.e., the volatility ratio and the durable-goods share should be negatively related. Through the broad credit channel, because large firms are thought to have information and transaction-cost advantages in dealing with banks, large firms are less affected by volatile monetary policy. In other words, the volatility reduction should be smaller for states with relatively large firms, i.e., the relationship between the volatility ratio and average firm size should be positive.

Through the narrow credit channel, because large banks have more alternative funding sources when monetary policy is tight, states in which large banks are relatively more important should be less affected by volatile monetary policy. In other words, these states should experience relatively smaller reductions in volatility, i.e., there should be a positive relationship between the volatility ratio and the deposit share of the three largest banks. In terms of the signs of the relationships between these variables and the break dates, if the monetary policy hypothesis is correct, we should see some relationship between the break date and manufacturing share, average firm size, and the deposit share of the three largest banks. However, there is little theory to guide us in determining the signs of the relationships. This is because, unlike the other two hypotheses, the link between monetary policy fluctuations and output fluctuations is indirect, meaning that there are lags through

\footnotetext{
${ }^{20}$ For detailed discussions of these channels, see, respectively, Cecchetti (1995); Bernanke and Blinder (1988); and Bernanke (1993); and Kashyap and Stein (1995, 2000).
} 
each monetary-policy channel between the change in monetary volatility and any resulting change in output volatility.

Tables 2 and 3 about here

Tables 2 and 3 summarize the relationships that we find between the volatility ratio and the various state characteristics. The difference between the two tables is that the latter has the results when we include the pre-break standard deviation of employment. According to Table 2, there is a positive and statistically significant relationship between the volatility ratio and the durable-goods share, but not the nondurable-goods share: the larger a state's durable-goods sector was, the larger was the reduction in volatility. This result is consistent with all three hypotheses. None of the coefficients on the other variables to test for the effects of the three hypotheses are statistically different from zero, however.

Note that when we include the pre-break standard deviation (Table 3), its coefficient is negative and statistically significant and the coefficient on the durable-goods share remains negative and statistically significant, although somewhat smaller. This indicates that the volatility reductions were not coming solely through durable-goods, but also were based more broadly. States that started with more-volatile output tended to see larger reductions in volatility following their break, whether or not the initial volatility was associated with durable-goods. These results suggest that whatever led to reductions in the volatility of output, it was not confined to the durable-goods sector. In terms of the three hypotheses, this weakens the evidence in favor of the good luck and inventories hypotheses relative to the monetary hypothesis.

Table 4 about here

As summarized in Table 4, the relationships between state characteristics and break 
dates seem to contradict two of the three hypotheses. In particular, the coefficient on the durable-goods share is statistically no different from zero, although the coefficients on the nondurable-goods and extractive-industries shares are both positive and statistically significant. The positive signs of these coefficients suggest that neither the good luck hypothesis nor the inventories hypothesis can explain the volatility reduction. These hypotheses suggest that states with higher manufacturing shares (inventories- or productivity-driven volatility reduction) or extractive shares (oil-driven volatility reduction) should lead other states. However, the higher a state's share of employment in either of these sectors was, the later it tended to break. On the other hand, the fact that we find statistically significant relationships between break dates and nondurable-goods share and average firm size indicate that at least two channels of monetary policy might have played a role in generating the break in output volatility. In concert with our results in Tables 2 and 3 , we find, therefore, that of the three hypotheses, the monetary policy hypothesis is most consistent with the volatility reductions that we document to have occurred at the state level.

Note that this does not mean that good luck and the reduction in energy-price volatility did not occur, nor that they did not lead to reductions in the volatility of output. However, it does mean that if these events did occur, they did not lead to the sharp reductions in output volatility that correspond to the structural breaks that we detect at the state level. For instance, energy prices tended to fluctuate well into the 1980s, which meant that a significant number of states with large energy sectors experienced their breaks later than other states, thereby accounting for the positive effect of extractive-industries share on the break date. In this sense, for these states the persistent volatility of energy prices delayed the reduction in output volatility that had been induced elsewhere by other factors, which we presume to have been monetary policy. Similarly, inventory management may indeed 
have improved and have contributed to the reduction in volatility, but it does not appear that such an improvement occurred in advance of or coincident with the break dates.

\section{Conclusion}

Much of the debate about the origin of the aggregate reduction in volatility has centered around three hypotheses: improved inventory management, better monetary policy, and good luck manifested as a decline in the frequency and magnitude of exogenous shocks. We exploit cross-sectional heterogeneity in the timing and magnitude of state-level volatility reductions to evaluate the plausibility of each of these hypotheses. Consistent with much of the previous literature, we find that manufacturing share does appear to play a significant role in determining the size of a state's volatility reduction. However, when we account for a state's initial volatility, manufacturing share no longer statistically influences the magnitude of that state's volatility reduction. Our results show that, for employment, demographics and initial volatility are the only statistically relevant determinants of the size of the volatility decrease.

The key variable in differentiating between the three alternative hypotheses is the timing of the decline in volatility for each state. We find that increasing either a state's manufacturing share or extractive share leads to, on average, a later volatility break. We interpret these results as evidence that improved inventory management or less volatile energy or productivity shocks could not have caused the Great Moderation. Instead, we

find that our results are more consistent with the theory that improved monetary policy was the most significant contributor to the volatility reduction. 


\begin{tabular}{|c|c|c|c|c|c|c|c|c|c|c|c|}
\hline \multicolumn{10}{|c|}{ Table 1: State Contributions to Aggregate Volatility Reduction } \\
\hline State & $\sigma_{i}^{2}$ & $\mu_{1 i}$ & State & $\sigma_{i}^{2}$ & $\mu_{1 i}$ & State & $\sigma_{i}^{2}$ & $\mu_{1 i}$ & State & $\sigma_{i}^{2}$ & $\mu_{1 i}$ \\
\hline AL & 0.005 & 0.006 & IA & 0.004 & 0.006 & NE & 0.001 & 0.001 & RI & 0.001 & 0.000 \\
\hline AZ & 0.002 & 0.003 & KS & 0.003 & 0.002 & NV & 0.001 & 0.002 & SC & 0.001 & 0.003 \\
\hline AR & 0.004 & 0.005 & KY & 0.008 & 0.008 & NH & 0.001 & 0.001 & SD & 0.001 & 0.000 \\
\hline CA & 0.033 & 0.051 & LA & 0.005 & 0.000 & NJ & 0.010 & 0.009 & TN & 0.005 & 0.008 \\
\hline CO & 0.004 & 0.002 & ME & 0.001 & 0.000 & NM & 0.001 & 0.000 & TX & 0.012 & 0.016 \\
\hline CT & 0.004 & 0.008 & MD & 0.003 & 0.002 & NY & 0.021 & 0.004 & UT & 0.001 & 0.003 \\
\hline DE & 0.002 & 0.000 & MA & 0.006 & 0.004 & NC & 0.005 & 0.008 & VT & 0.000 & 0.000 \\
\hline DC & 0.000 & 0.000 & MI & 0.026 & 0.051 & ND & 0.001 & 0.000 & VA & 0.004 & 0.004 \\
\hline FL & 0.008 & 0.014 & MN & 0.005 & 0.012 & OH & 0.033 & 0.049 & WA & 0.004 & 0.008 \\
\hline GA & 0.004 & 0.006 & MS & 0.003 & 0.003 & OK & 0.001 & 0.000 & WV & 0.002 & 0.000 \\
\hline ID & 0.001 & 0.001 & MO & 0.010 & -0.002 & OR & 0.002 & 0.007 & WI & 0.008 & 0.014 \\
\hline IL & 0.021 & 0.026 & MT & 0.001 & 0.000 & PA & 0.026 & 0.035 & WY & 0.001 & 0.000 \\
\hline IN & 0.015 & 0.023 & & & & & & & & \\
\hline
\end{tabular}




\begin{tabular}{|c|c|c|c|}
\hline \multicolumn{5}{|c|}{ Table 2: Volatility Reduction and State Characteristics I } \\
\hline \multicolumn{4}{|c|}{ Dependent Variable = Pre-Break Volatility/Post-Break Volatility } \\
\hline$R^{2}=0.503$ & Coefficient & Robust s.e. $^{\dagger}$ & t-stat $^{-1}$ \\
\hline Average nondurables share & 0.00002 & 0.0060 & 0.00 \\
\hline Average durables share & -0.0063 & 0.0033 & -1.90 \\
\hline Average extractive share & -0.0121 & 0.0106 & -1.14 \\
\hline Average firm size & 0.0044 & 0.0050 & 0.89 \\
\hline Deposit share of 3 largest banks & -0.0003 & 0.0007 & -0.39 \\
\hline Average share w/4 or more yrs. of HS & -0.0024 & 0.0029 & -0.82 \\
\hline Average share aged 18-44 & 0.0240 & 0.0037 & 6.56 \\
\hline Constant & -0.1318 & 0.2773 & -0.48 \\
\hline
\end{tabular}

$\dagger$ White heteroskedasticity-consistent standard errors 


\begin{tabular}{|c|c|c|c|}
\hline \multicolumn{5}{|c|}{ Table 3: Volatility Reduction and State Characteristics II } \\
\hline \multicolumn{3}{|c|}{ Dependent Variable = Pre-Break Volatility/Post-Break Volatility } \\
\hline$R^{2}=0.575$ & Coefficient & Robust s.e. $^{\dagger}$ & t-stat $^{-1}$ \\
\hline Pre-break standard deviation & -0.3466 & 0.1284 & -2.70 \\
\hline Average nondurables share & 0.0016 & 0.0039 & 0.41 \\
\hline Average durables share & -0.0054 & 0.0028 & -1.91 \\
\hline Average extractive share & -0.0032 & 0.0110 & -0.29 \\
\hline Average firm size & 0.0028 & 0.0047 & 0.59 \\
\hline Deposit share of 3 largest banks & 0.0002 & 0.0007 & 0.29 \\
\hline Average share w/4 or more yrs. of HS & -0.0018 & 0.0023 & -0.77 \\
\hline Average share aged 18-44 & 0.0233 & 0.0041 & 5.66 \\
\hline Constant & -0.0049 & 0.2242 & -0.02 \\
\hline
\end{tabular}

$\dagger$ White heteroskedasticity-consistent standard errors 


\begin{tabular}{|c|c|c|c|}
\hline \multicolumn{5}{|c|}{ Table 4: Break Dates and State Characteristics } \\
\hline \multicolumn{4}{|c|}{ Dependent Variable $=$ Break Month $(1956: 01=0)$} \\
\hline$R^{2}=0.301$ & Coefficient & Robust s.e. $^{\dagger}$ & t-stat $^{-5}$ \\
\hline Average nondurables share & 5.4731 & 1.6873 & 3.24 \\
\hline Average durables share & 0.8506 & 1.3091 & 0.65 \\
\hline Average extractive share & 6.4604 & 2.0962 & 3.08 \\
\hline Average firm size & -4.6832 & 2.8338 & -1.65 \\
\hline Deposit share of 3 largest banks & 0.3812 & 0.3020 & 1.26 \\
\hline Average share w/4 or more yrs. of HS & -0.0215 & 1.0342 & -0.02 \\
\hline Average share aged 18-44 & -0.9055 & 2.0947 & -0.43 \\
\hline Constant & 361.8714 & 94.9520 & 3.81 \\
\hline
\end{tabular}

$\dagger$ White heteroskedasticity-consistent standard errors 


\section{References}

[1] Ahmed, Shaghil; Levin, Andrew; and Wilson, Beth Anne (2004), "Recent U.S. Macroeconomic Stability: Good Policies, Good Practices, or Good Luck?" Review of Economics and Statistics, 86(3), pp. 824-832.

[2] Anderson, Heather and Vahid, Farshid (2003), "The Decline in Income Growth Volatility in the United States: Evidence from Regional Data," Monash Econometrics and Business Statistics Working Paper No. 21/2003, Monash University.

[3] Bernanke, Ben S. (1993), "Credit in the Macroeconomy," Federal Reserve Bank of New York Quarterly Review, 18(1), pp. 50-70.

[4] Bernanke, Ben S. and Blinder, Alan S. (1988), "Credit, Money, and Aggregate Demand," American Economic Review: Papers and Proceedings, 78(2), pp. 435-439.

[5] Boivin, Jean and Giannoni, Marc P. (2003), "Has Monetary Policy Become More Effective?" NBER Working Paper No. 9459.

[6] Carlin, Bradley P.; Gelfand, Alan E.; and Smith, Adrian F.M. (1992), "Hierarchical Bayesian Analysis of Changepoint Problems," Applied Statistics, 41(2), pp. 389-405.

[7] Carlino, Gerald; DeFina, Robert; and Sill, Keith (2004), "On the Stability of Employment Growth: A Postwar View from the U.S. States," Federal Reserve Bank of Philadelphia Working Paper No. 04-21/R.

[8] Cecchetti, Stephen G. (1995), "Distinguishing Theories of the Monetary Transmission Mechanism," Federal Reserve Bank of St. Louis Review, 77(3), pp. 83-97.

[9] Chauvet, Marcelle and Potter, Simon (2001), "Recent Changes in the U.S. Business Cycle," Manchester School, 69(5), pp. 481-508. 
[10] Crone, Theodore M. and Clayton-Matthews, Alan (2005) "Consistent Economic Indexes for the 50 States," Review of Economics and Statistics.

[11] Gelfand, Alan E. and Smith, Adrian F.M. (1990), "Sampling-Based Approaches to Calculating Marginal Densities," Journal of the American Statistical Association, 85(410), pp. 398-409.

[12] Hamilton, James D. (1989), "A New Approach to the Economic Analysis of Nonstationary Time Series and the Business Cycle," Econometrica, 57(2), pp. 357-384.

[13] Herrera, Ana Maria and Pesavento, Elena (forthcoming), "The Decline in U.S. Output Volatility: Structural Change and Inventory Investment," Journal of Business and Economic Statistics.

[14] Jeffreys, Harold (1961), Theory of Probability, Oxford, U.K.: Clarendon Press.

[15] Kahn, James A.; McConnell, Margaret M.; and Perez-Quiros, Gabriel (2000), "Inventories and the Information Revolution: Implications for Output Volatility," Federal Reserve Bank of New York, mimeo.

[16] Kashyap, Anil K. and Stein, Jeremy C. (1995), "The Impact of Monetary Policy on Bank Balance Sheets," Carnegie-Rochester Conference Series on Public Policy, 42(0), pp. 151-195.

[17] Kashyap, Anil K. and Stein, Jeremy C. (2000), "What Do a Million Observations on Banks Say About the Transmission of Monetary Policy?" American Economic Review, 90(3), pp. 407-428.

[18] Kim, Chang-Jin and Nelson, Charles R. (1999a), "Has the U.S. Economy Become More Stable? A Bayesian Approach Based on a Markov-Switching Model of the Business Cycle," Review of Economics and Statistics, 81(4), 608-616. 
[19] Kim, Chang-Jin and Nelson, Charles R. (1999b), State-Space Models with Regime Switching: Classical and Gibbs-Sampling Approaches with Applications, Cambridge: MIT Press.

[20] Kim, Chang-Jin; Nelson, Charles R.; and Piger, Jeremy (2004), "The Less-Volatile U.S. Economy: A Bayesian Investigation of Timing, Breadth, and Potential Explanations," Journal of Business and Economic Statistics, 22(1), pp. 80-93.

[21] McConnell, Margaret M. and Perez-Quiros, Gabriel (2000), "Output Fluctuations in the United States: What Has Changed Since the Early 1980's?" American Economic Review, 90(5), pp. 1464-1476.

[22] Owyang, Michael T.; Piger, Jeremy; and Wall, Howard J. (2005), "Business Cycle Phases in U.S. States," Review of Economics and Statistics.

[23] Ramey, Valerie A. and Vine, Daniel J. (2004), "Tracking the Source of the Decline in GDP Volatility: An Analysis of the Automobile Industry," University of California, San Diego, mimeo.

[24] Stock, James H. and Watson, Mark W. (2002), "Has the Business Cycle Changed and Why?" In NBER Macroeconomics Annual 2002, Mark Gertler and Ken Rogoff (eds), Cambridge: MIT Press, pp. 159-218. 
Figure 1: Evidence for Model with Break

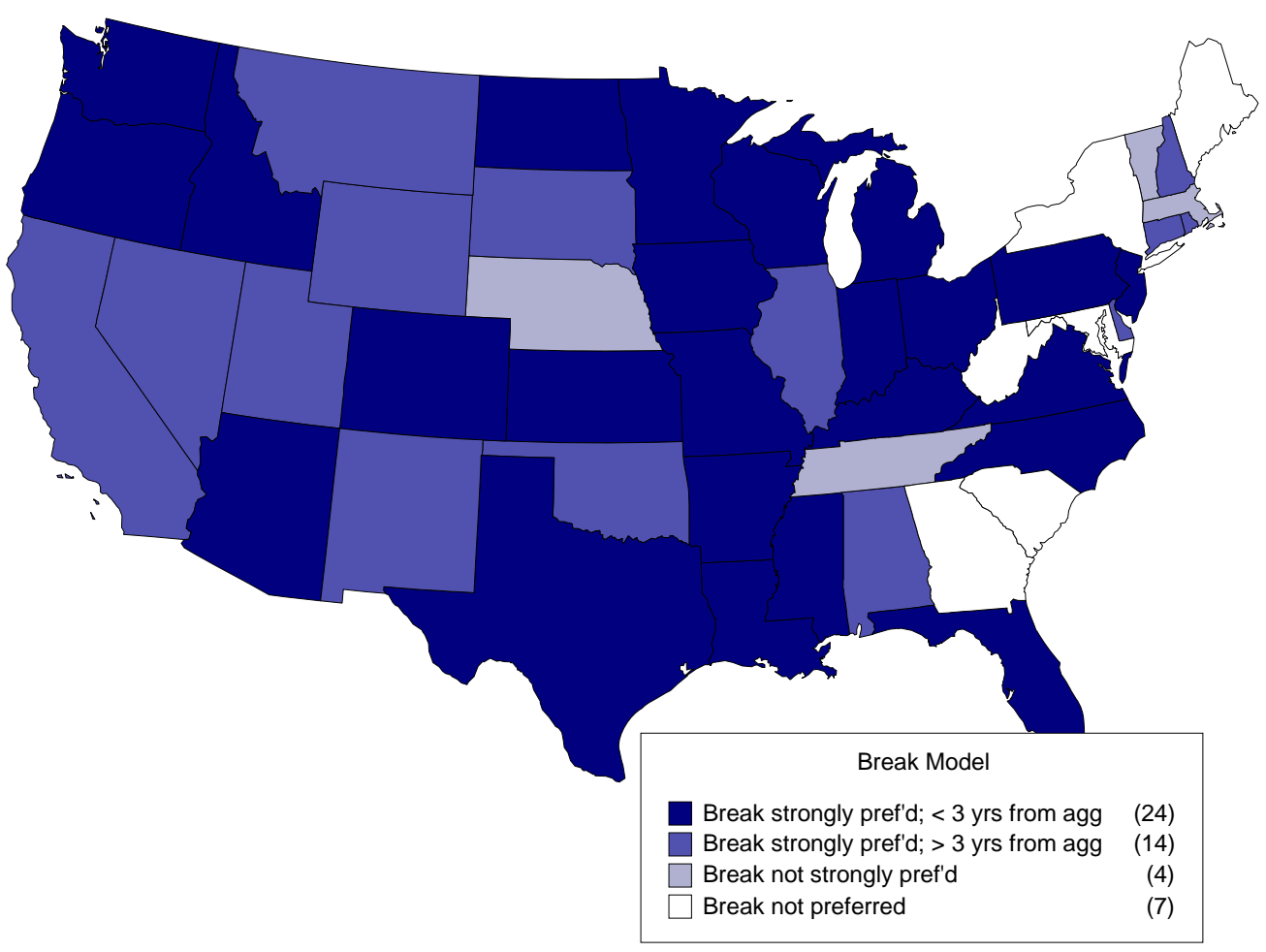

Figure 2: Break Timing Across States

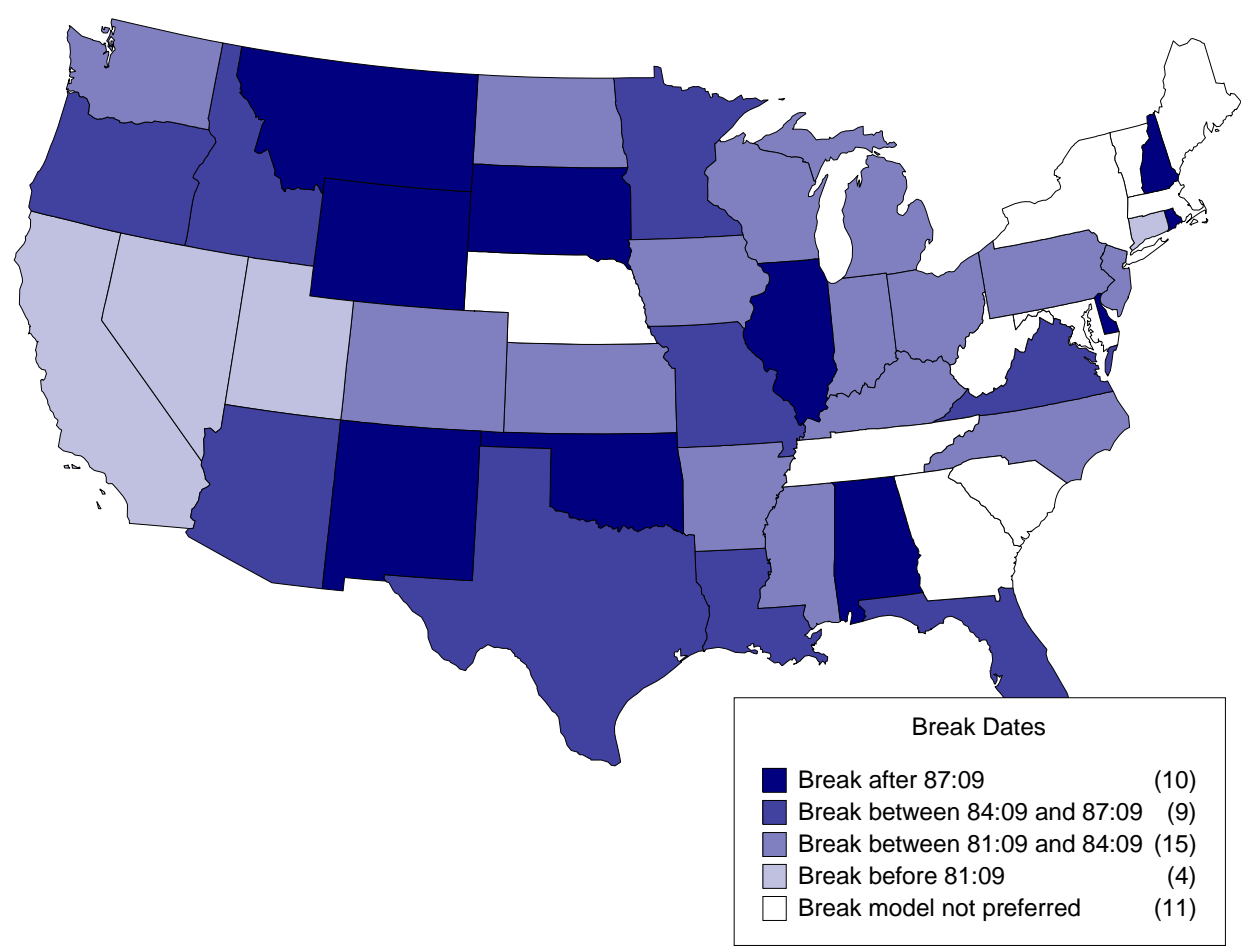


Figure 3: Magnitude of Volatility Reduction

$\mathrm{X}=$ Ratio of state post-break volatility to pre-break volatility

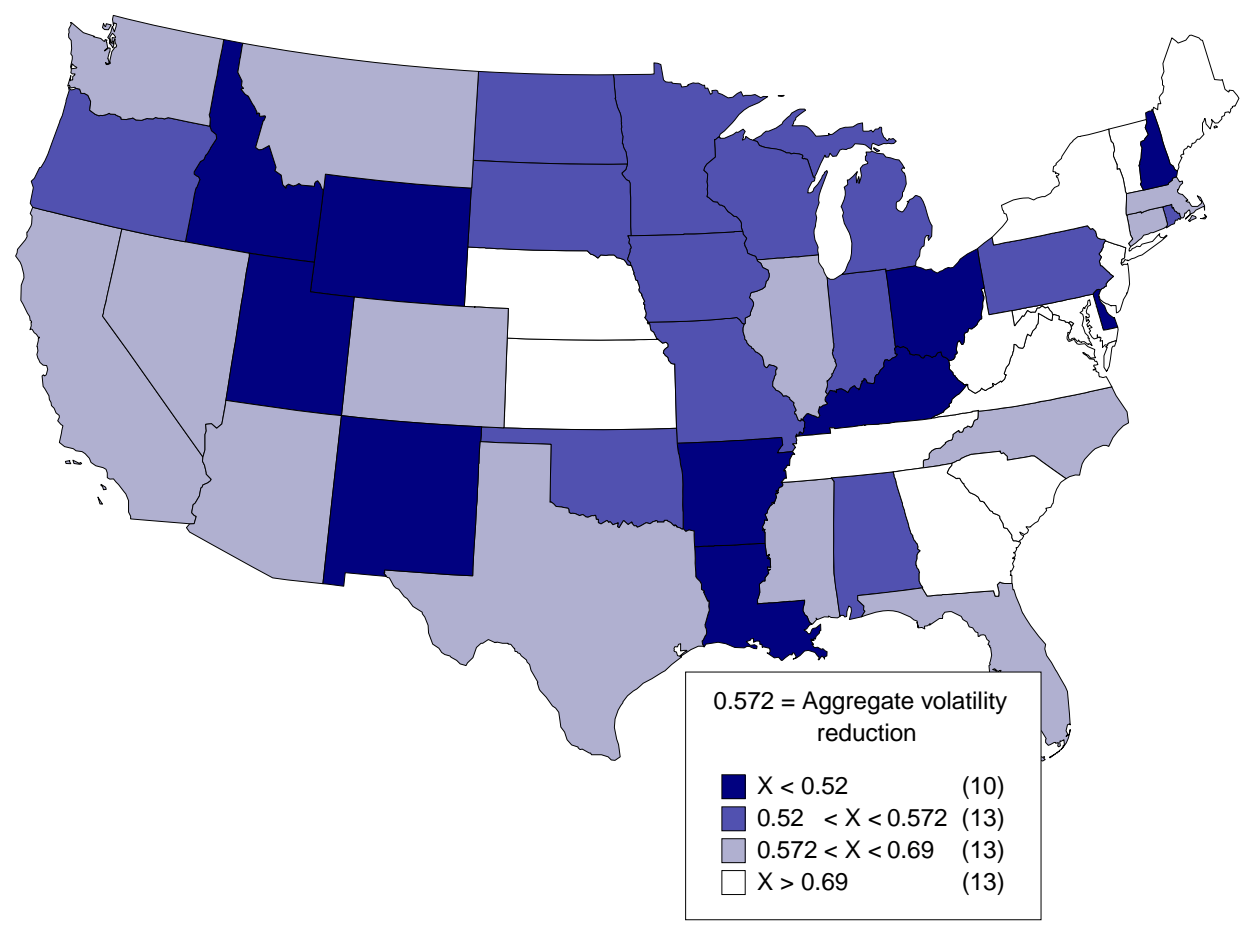

Figure 4: State Volatility Reduction Composition

Ratio of volatility reduction caused by business cycle to total volatility reduction

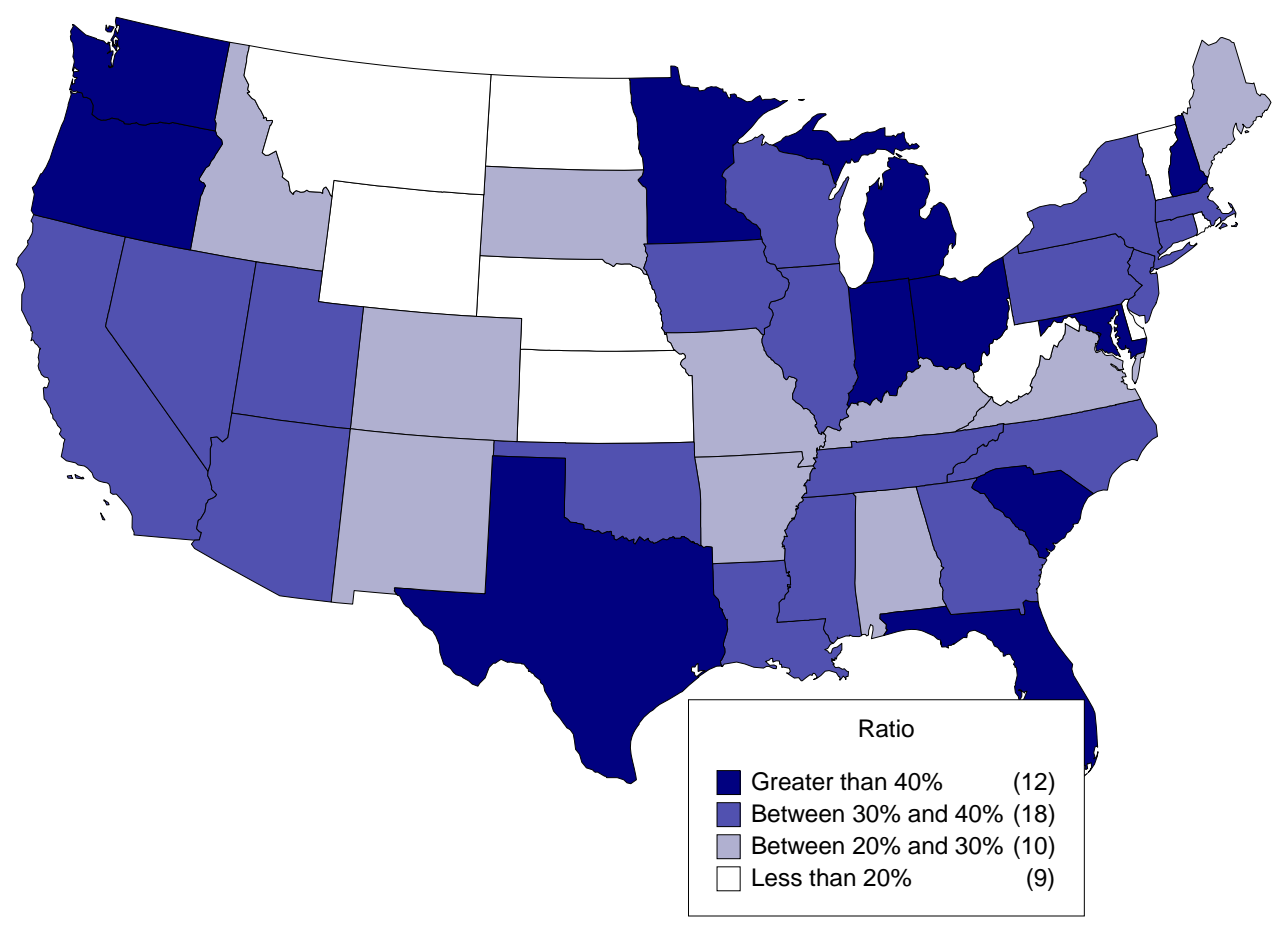

